\title{
Supply-demand relationship of cabs
}

\author{
Juanjuan $\mathrm{Hu}$ \\ North China Electric Power University, Baoding 071000, China
}

Keywords: supply-demand relationship; equilibrium function; regulation.

\begin{abstract}
This paper mainly discusses the relationship of supply-demand after strengthening the regulations of cab companies. Aiming to find the balance point from Demand function and Supply function, we build the equilibrium price decision model. Because of the banning of nonstandard cabs, the number of cabs will drop without new supplies. Following by it, there would be an inflation of prices. On the other hand, there will be more residents to ride a cab because quality of service improved.
\end{abstract}

\section{Introduction}

Mythical is a vital college town. Accepting some personal-car owners, there is still a large population, can't be ignored, and depends on public transportation and taxicabs. Owing to the low satisfaction, the resource of cabs cannot be taken good advantage of seemingly.

Because the city of Mythical is fictional, we require certain population and area to solve the models for which we study an existing town named Tompkins.

We mainly tackle this problem:

What would be the likely consequences of strengthening the regulations against unlicensed/livery companies (currently controlling about $1 / 7$ of all cabs in the city)?

To tackle the question, we establish the supply-demand model based on the western economy. Then we analysis the variations after enhancing the regulation of cab market qualitatively and seek the equilibrium.

\section{Assumptions}

[1] Without considering the population migration.

[2] The price of cab only influenced by the supply-demand relationship

[3] Neglect the restraints of customers' economic conditions

3. Supply-demand relationship after strengthening the regulations of cab market

\subsection{Symbol description}

\begin{tabular}{c|c}
\hline Symbol & Symbol meaning \\
\hline$S$ & The supplication of cabs \\
\hline$D$ & The demand of cabs, \\
\hline$P$ & The cost to ride a cab \\
\hline$Q$ & No load ratio \\
\hline
\end{tabular}




\subsection{The building of the model}

What we research is the supply-demand relationship between cabs and passengers. So we establish the equilibrium price decision model based on the economy theory.

We describe the relationship by Demand function - - a function that relates the demand to price and Supply function — - a function that relates the supply to price.

The formula of Demand function is as follows:

$\mathrm{Q}^{d}=\alpha-\beta \bullet P \quad(\alpha, \beta=$ const,$\alpha 、 \beta>0)$

Where $-\beta=\lim _{\Delta P \rightarrow 0} \frac{\Delta Q^{d}}{\Delta P}=\frac{d Q^{d}}{d P}$

The formula of Supply function is as follows:

$Q^{S}=-\delta+\gamma \bullet P \quad(\delta 、 \gamma=$ const, $\delta 、 \gamma>0)$

Here $Q^{S}>0$

It means that the price of riding cab must meet the equation:

$P>\frac{\delta}{\gamma}$

And $\gamma=\lim _{\Delta P \rightarrow 0} \frac{\Delta Q^{S}}{\Delta P}=\frac{d Q^{S}}{d P}$

On account of the balance between supply and demand, there is an equation between $Q^{S}$ and $Q^{d}$. The curve is as follows:

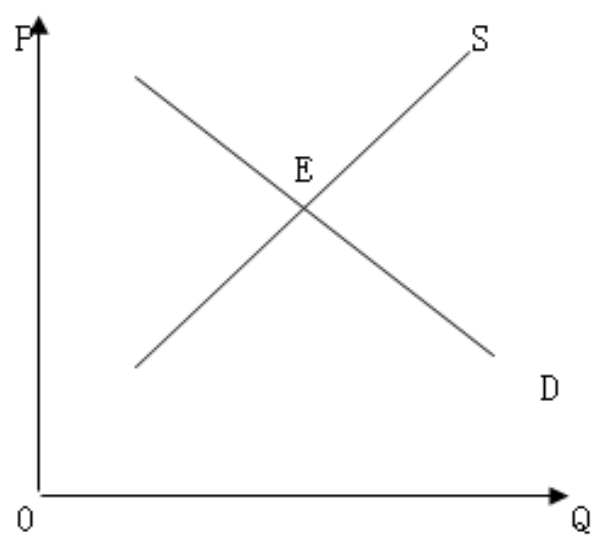

P: The price of cabs

Q: The number of cabs

S: Supply function: A function that relates the quantity supplied to price.

E: equilibrium: No change in behavior will be observed.

When we strengthen the standardization, all unlicensed/livery companies cannot operate normally as we learned in the title. It means the total amount of taxis will be reduced and we need to take more to ride a cab. When the demand function or the demand function fluctuates regularly, the balance will be broken. But the balance will be rebuilt automatically under the function of market mechanism. In consideration of the number of trips remains unchanged roughly, the movement of the supply-demand relationship is as follows:

Where the E' is the new balanced point.

Due to the unlicensed companies are primarily responsible for the low customer satisfaction, residents will be more active to ride a cab after enhancing the regulations, in another word ,the cab travel number will improve: 

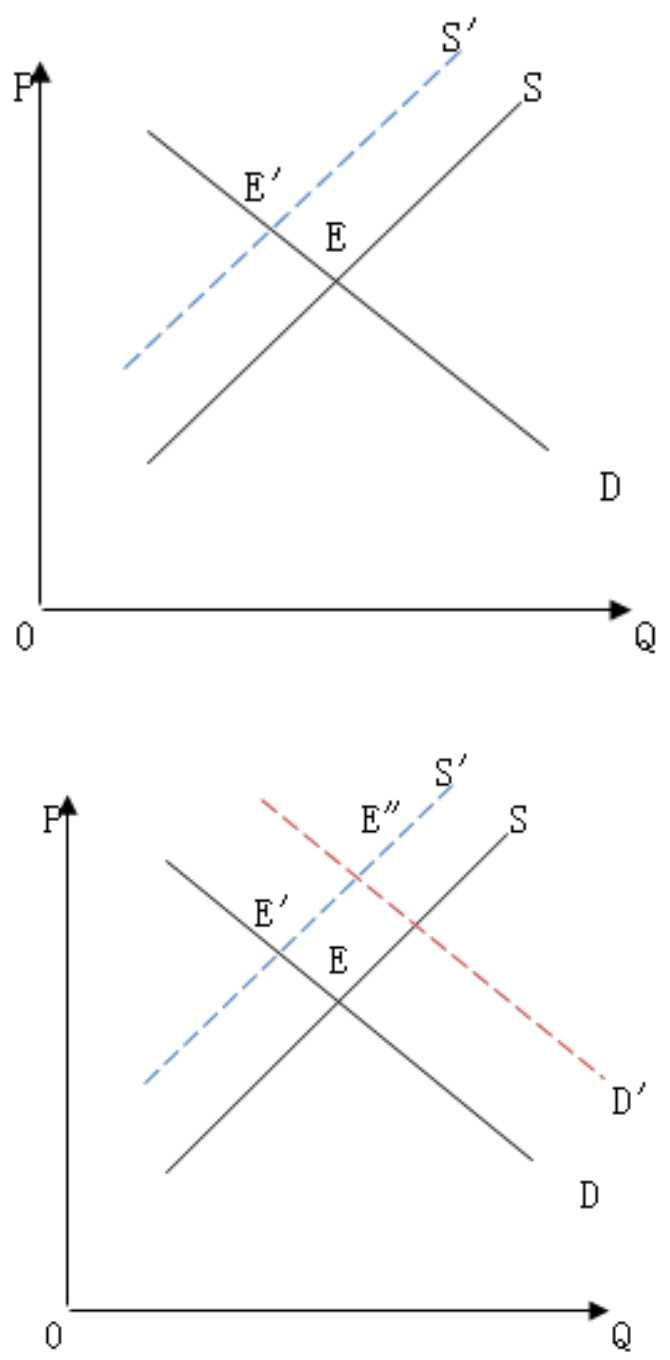

Where the E” is the present balanced point.

\subsection{Conclusion}

Through the above analysis, we can know that the price of the cab will improve, but the no load ratio may not be reduced, on the contrary, may be risen. So we'd better come up with efficient measures before reinforcing the regulation.

\subsection{The comparison of the price}

If the cost for riding a cab is non-regulated, in consideration of the number of the cabs in the center and airport is much more than others. On the basis of the economics, we can know: when the cabs are oversupply, the price will fall to a certain extent as the fiercer competitive.

Our analysis is as follows:

We regard the cab as a monopoly enterprise when it is managed uniformly. And when we ride have no regelation, the existence of price discrimination cannot be ignored in monopoly enterprise. (Selling different units of output at different prices is called price discrimination) Second-degree price discrimination is the major component above it. (The monopolist sells different units of output for different prices, but every individual who buys the same amount of the good pays the same price). Then it turns into perfect competition after independent management. (Perfect competition is an ideal market structure in which have no hinders to ensure the full competitive).

\subsection{Strengths and Weaknesses}

Strengths. Comparisons properly used in the paper make the variation evident. 
Weaknesses. The same as the model 2, we lack analyses quantitatively.

\section{References}

[1] The Study on Mathematical Models of Population Growth in Huanggang City (SHAO Xiao-feng, ZHANG Ke-xin)

[2] Planning Model of Taxi Based on Trip Intensity

(XIEJin song1, TANG Re qing1, YANGShu2, SUXiao Jun)

[3]Intermediate microeconomics 8e.Hal r. Varian

[4] Western Economy GAO Hong-ye

[5] The United States Census Bureau: http://www.census.gov/popest/about/terms.html

[6] http://www.fhwa.dot.gov/policy/2013cpr/chap1.htm

[7] Research on trip distance distribution model and parameter(Shi Fei , Lu Zhen-bo) 